\title{
Synthesis of Micro-Sized Titanium Dioxide Nanosheets Wholly Exposed with High-Energy $\{001\}$ and $\{100\}$ Facets
}

\author{
Ci Zhang Wen ${ }^{a}$, Ji Zhi Zhou ${ }^{\mathrm{b}}$, Hai Bo Jiang ${ }^{a}$, Qiu Hong Hu ${ }^{\mathrm{b}}$, Shi Zhang Qiao*b, Hua Gui Yang*a \\ Received (in XXX, XXX) Xth XXXXXXXXX 200X, Accepted Xth XXXXXXXXX 200X \\ First published on the web $X t h X X X X X X X X X 200 X$ \\ DOI: 10.1039/b000000x
}

\begin{abstract}
A new synthetic strategy was developed to prepare large-sized well-defined anatase $\mathrm{TiO}_{2}$ nanosheets wholly dominated with thermodynamically unfavorable high-reactive $\{001\}$ and $\{100\}$ facets, which has a percentage of $98.7 \%$ and $1.3 \%$, respectively. The as-prepared anatase $\mathrm{TiO}_{2}$ nanosheets show a well-faceted morphology and have a large size in length (ca. $4.14 \mu \mathrm{m})$. The formation mechanism of the anatase $\mathrm{TiO}_{2}$ nanosheets was also analyzed and investigated.
\end{abstract}

In recent years, intensive research attention has been paid to design and synthesis of functional inorganic crystals with exposed high-energy surfaces, which normally show excellent physiochemical properties because of their unique geometrical and electronic structures such as high densities of atom steps, kinks, dangling bonds, and ledges. ${ }^{1-3}$ Titanium dioxide $\left(\mathrm{TiO}_{2}\right)$ has been extensively studied due to its many industrial applications such as photovoltaic cells, photo/electrochromics, photocatalysis, photonic crystals, smart surface coatings, rechargeable lithium batteries, sensors, and so on. ${ }^{4-8}$ For anatase $\mathrm{TiO}_{2}$, both theoretical and experimental studies found that both $\{001\}$ and $\{100\}$ facets in the equilibrium state are especially reactive. ${ }^{9}$ Unfortunately, due to the minimization of surface energy during the process of crystal growth, most available anatase $\mathrm{TiO}_{2}$ nanocrystals were dominated by the thermodynamically stable $\{101\}$ facets other than the more reactive $\{001\}$ or $\{100\}$ facets $\left(0.90 \mathrm{~J} / \mathrm{m}^{2}\right.$ for $\{001\} ;>0.53 \mathrm{~J} / \mathrm{m}^{2}$ for $\{100\} ;>0.44 \mathrm{~J} / \mathrm{m}^{2}$ for $\left.\{101\}\right) .{ }^{9-11}$

On the basis of theoretical predictions, for the first time we have successfully synthesized uniform anatase $\mathrm{TiO}_{2}$ single crystals with a high percentage $(47-64 \%)$ of $\{001\}$ facets using hydrofluoric acid as a morphology controlling agent. ${ }^{12,13}$ Following these breakthroughs, various reaction systems or capping agents have been recently exploited to achieve $\mathrm{TiO}_{2}$ with exposed high-reactive $\{001\}$ and $\{100\}$ facets. ${ }^{14-21}$ For instance, by hydrothermal reaction of tetrabutyl titanate and

\footnotetext{
${ }^{a}$ Key Laboratory for Ultrafine Materials of Ministry of Education, School of Materials Science and Engineering, East China University of Science and Technology, 130 Meilong Road, Shanghai 200237 China; Fax: 8621 64252127; Tel: 8621 64252127; E-mail: hgyang@ecust.edu.cn

${ }^{b}$ The University of Queensland, ARC Centre of Excellence for Functional Nanomaterials, Australian Institute for Bioengineering and Nanotechnology, QLD 4072, Australia; Fax: 617 33463973; Tel: 617 33463815; E-mail: s.qiao@uq.edu.au

$\dagger$ Electronic Supplementary Information (ESI) available: Experimental details, XRD, Raman spectra, XPS, SEM images of the as-obtained $\mathrm{TiOF}_{2}$ and photocatalytic property for $\mathrm{H}_{2}$ generation.
}

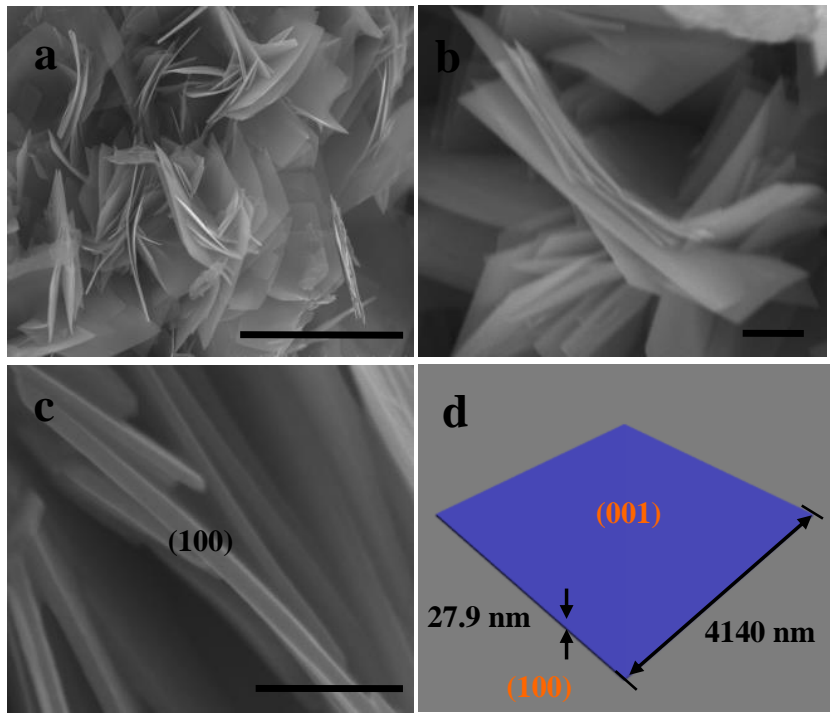

Fig. 1 a), b) and c) FESEM images of anatase $\mathrm{TiO}_{2}$ nanosheets synthesized at $210{ }^{\circ} \mathrm{C}$ for $24 \mathrm{~h}$. d) Schematic structure of the as-obtained anatase $\mathrm{TiO}_{2}$ nanosheets. Scale bars in (a-c) are $5.0 \mu \mathrm{m}, 2.0 \mu \mathrm{m}$, and $300 \mathrm{~nm}$, respectively.

hydrofluoric acid (HF), Han et al. ${ }^{14}$ synthesized nano-sized sheet-like anatase $\mathrm{TiO}_{2}$ with up to $89 \%$ of $\{001\}$ facets and average size length of $30-130 \mathrm{~nm}$, which showed superior photocatalytic performance. Furthermore, by using Na-titanate nanotubes as solid precursor, $\mathrm{TiO}_{2}$ single crystals with active $\{100\}$ facets have recently prepared under hydrothermal conditions. ${ }^{16}$

Just like one-atom-thick planar graphene sheet, activesurface dominated anatase $\mathrm{TiO}_{2}$ nanosheets might extend many applications of this important semiconducting material. Even though anatase $\mathrm{TiO}_{2}$ with dominant $\{001\}$ or $\{100\}$ was prepared recently, to the best of our knowledge, preparing well-faceted anatase $\mathrm{TiO}_{2}$ single crystalline nanosheets wholly exposed with $\{001\}$ and $\{100\}$ facets have not been synthesized so far. Both theoretical predictions and experimental results indicates that hydroxyl groups can lower the surface energy of $\{100\}$ facets significantly and the oxygenated surface may lead to formation of $\{100\}$ facets, which means that only in basic conditions can $\{100\}$ facets be formed. On the other hand, previous experimental results testified that $\{001\}$ facets were generally generated under acidic conditions. Thus preparing anatase $\mathrm{TiO}_{2}$ exposed by $\{001\}$ and $\{100\}$ facets instead of thermodynamically stable 
low-reactive $\{101\}$ facets is highly desired and still remains a challenge. Furthermore, because of the low structural stability of high-active surface during the crystal growth process (i.e., $1 \times 4$ reconstruction), for ultrathin anatase $\mathrm{TiO}_{2}$ nanosheets dominated with $\{001\}$ facets, the length along [100] crystallographic direction is only around $100 \mathrm{~nm}$ and it is thus also quite challenging to prepare well-faceted large-sized anatase $\mathrm{TiO}_{2}$ nanosheets, which might have great potential applications.

Herein we report a facial synthetic method for the preparation of large-sized anatase $\mathrm{TiO}_{2}$ nanosheets wholly dominated with high-reactive $\{001\}$ and $\{100\}$ facets, which have percentages of $98.7 \%$ and $1.3 \%$, respectively. The asprepared anatase $\mathrm{TiO}_{2}$ nanosheets show a well-faceted morphology and have a unique large size in length ( $c a .4 .14$ $\mu \mathrm{m})$. The formation mechanism of the anatase $\mathrm{TiO}_{2}$ nanosheets entirely dominated by high-reactive crystallographic facets is also discussed using the experimental results of early reaction stage.

Large-sized anatase $\mathrm{TiO}_{2}$ nanosheets wholly exposed with high-energy $\{001\}$ and $\{100\}$ facets were prepared through a solvothermal route at $210{ }^{\circ} \mathrm{C}$ for $18-24 \mathrm{~h}$, wherein titanium tetrafluoride $\left(\mathrm{TiF}_{4}\right)$ was transferred to titanium oxydifluoride $\left(\mathrm{TiOF}_{2}\right)$ first and then anatase $\mathrm{TiO}_{2}$ in $20 \mathrm{~mL}$ of 1-butanol $\left(\mathrm{CH}_{3}\left(\mathrm{CH}_{2}\right)_{2} \mathrm{CH}_{2} \mathrm{OH}\right)$ solvent containing $0.2 \mathrm{~mL}$ of $48 \% \mathrm{HF}$. The crystallographic structure of the resulting products was evidenced by powder X-ray diffraction (XRD) (will be discussed in Fig. S1a), which reveals a phase-pure anatase $\mathrm{TiO}_{2}$ (space group I41/amd, JCPDS No. 21-1272). ${ }^{21}$ Fig. 1 shows the typical results of our field-emission scanning electron microscopy (FESEM) investigations. Lowmagnification SEM images in Fig. 1 $a$ and $b$ show the general morphology of the paper-like anatase $\mathrm{TiO}_{2}$ nanosheets which have a micro-size and also demonstrate some flexibility. In a high-magnification SEM image, the edges of these anatase $\mathrm{TiO}_{2}$ nanosheets are quite flat and smooth (see Fig. 1c), indicating that the edges should only contain one type of crystallographic facet. More SEM evidence is provided in Fig. S2, which indicates the same results. On the basis of the symmetries of anatase $\mathrm{TiO}_{2}$, the square surfaces must be $\{001\}$ facets and the other four rectangle surfaces are $\{100\}$ facets of the anatase $\mathrm{TiO}_{2}$ single crystals (further evidence is given in Fig. 2). The yield of anatase $\mathrm{TiO}_{2}$ nanosheets is nearly $100 \%$, even though some agglomerates were occasionally observed. To examine the uniformity of the synthesized anatase $\mathrm{TiO}_{2}$ nanosheets, the values of length and thickness of anatase $\mathrm{TiO}_{2}$ nanosheets were statistically analyzed. The average value of length is $4.14 \mu \mathrm{m}$ and the thickness is only $27.9 \mathrm{~nm}$. Thus we estimate the percentages of $\{001\}$ and $\{100\}$ facets to be $98.7 \%$ and $1.3 \%$, respectively. A schematic morphology of the as-synthesized anatase $\mathrm{TiO}_{2}$ nanosheets is also provided in Fig. $1 \mathrm{~d}$ and the values of the length and thickness are all proportional to the experimental results.

The results of transmission electron microscopy and selected-area electron diffraction (TEM/SAED) of anatase $\mathrm{TiO}_{2}$ nanosheets dominated with high-energy $\{001\}$ and $\{100\}$ facets are shown in Figs. 2 a-d. The selected-area electron diffraction patterns can be indexed into diffraction spots of
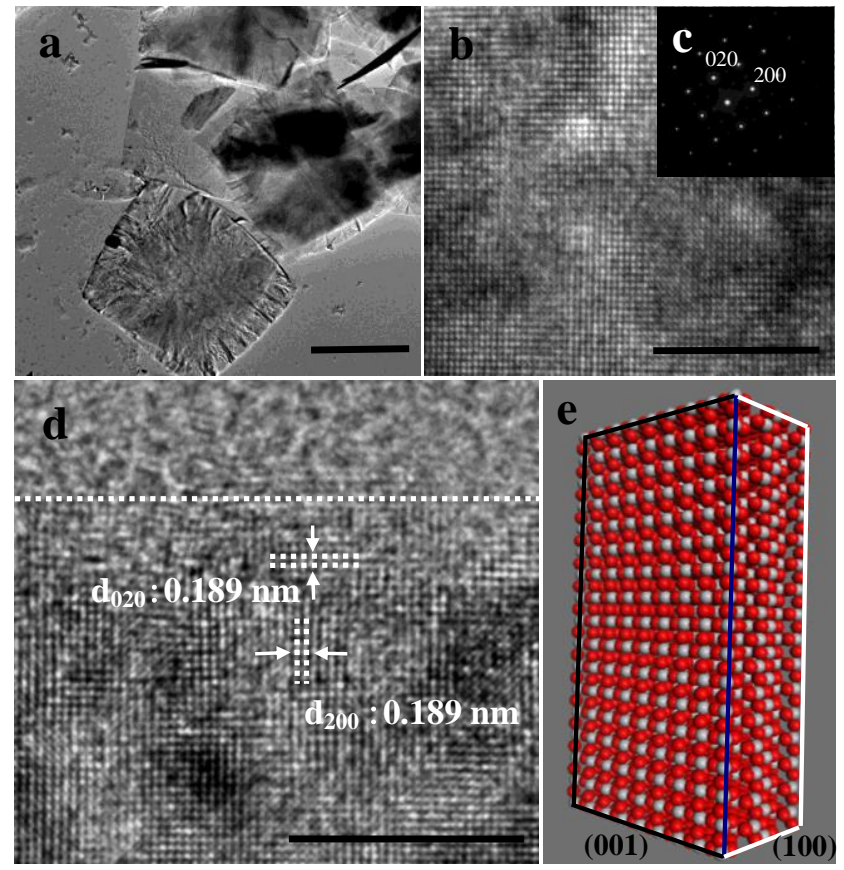

Fig. 2 a) TEM image of the anatase $\mathrm{TiO}_{2}$ nanosheets obtained at $210^{\circ} \mathrm{C}$ for $20 \mathrm{~h} . \mathrm{b}$ ) and c) HRTEM image and SAED pattern of the anatase $\mathrm{TiO}_{2}$ nanosheets (recorded on the central region of a free standing nanosheet). d) HRTEM image of anatase $\mathrm{TiO}_{2}$ nanosheets, which was recorded on the edge region. e) Schematic atomic model of the $\{100\}$ and $\{001\}$ boundary of anatase $\mathrm{TiO}_{2}$ nanosheets. Scale bars in a), b) and d) are 3.0 $\mu \mathrm{m}, 5.0 \mathrm{~nm}$, and $5.0 \mathrm{~nm}$, respectively.

the [001] zone. ${ }^{21}$ The high-resolution TEM image (Fig. 2b) in the central area of a free-standing anatase $\mathrm{TiO}_{2}$ nanosheet shows the (200) and (020) atomic planes with a lattice spacing of $1.89 \AA$ and an interfacial angle of $90^{\circ}$. More importantly, the high-resolution TEM image of the edge region (Fig. 2d) also indicates a relatively high crystallinity and well-faceted surface; this implies that the boundary between (001) and (100) surface is well constructed, which can be mimicked by the schematic structure shown in Fig. 2e. Moreover, Raman spectroscopy was applied to examine the crystal phase of anatase $\mathrm{TiO}_{2}$ nanosheets and the results show typical Raman spectrum of anatase $\mathrm{TiO}_{2}$ which has six modes appearing at $144 \mathrm{~cm}^{-1}\left(\mathrm{Eg}_{\mathrm{g}}\right), 197 \mathrm{~cm}^{-1}\left(\mathrm{E}_{\mathrm{g}}\right), 399 \mathrm{~cm}^{-1}\left(\mathrm{~B}_{1 \mathrm{~g}}\right), 513 \mathrm{~cm}^{-1}\left(\mathrm{~A}_{1 \mathrm{~g}}\right)$, $519 \mathrm{~cm}^{-1}\left(\mathrm{~B}_{1 \mathrm{~g}}\right)$, and $639 \mathrm{~cm}^{-1} \quad\left(\mathrm{E}_{\mathrm{g}}\right)$ (see Supporting Information, Fig. S3). ${ }^{22}$ This finding is also consistent with XRD results shown in Fig. S1a. In order to study the formation mechanism of the large-sized anatase $\mathrm{TiO}_{2}$ nanosheets wholly dominated with high-reactive $\{001\}$ and $\{100\}$ facets, the products at early reaction stage were collected and analyzed systematically. As indicated in Figs. 1, 2 and $\mathrm{S} 1 \mathrm{a}$, the $\mathrm{TiO}_{2}$ products with a reaction time of $18-24 \mathrm{~h}$ are only in pure anatase polymorph. However, under the same reaction media, if the reaction time is shorter than $17 \mathrm{~h}$, only $\mathrm{TiOF}_{2}$ crystals can be found (see Supporting Information, Fig. S4). XRD pattern in Fig. S1b clearly illustrates the pure cubical $\mathrm{TiOF}_{2}$ phase (space group Pm3m, JCPDS No. 08- 
0060).

The morphology of early stage products (cubical $\mathrm{TiOF}_{2}$ crystals) with a reaction time of $6 \mathrm{~h}$ was studied using SEM (Supporting Information, Fig. S4). From the symmetries of cubic $\mathrm{TiOF}_{2}$ crystals, all the flat, square surfaces can be indexed into $\{100\}$ facets. These well-faceted crystals show an average length of $4.3 \mu \mathrm{m}$, which is quite comparable to that of the final anatase $\mathrm{TiO}_{2}$ nanosheets. From these results, it can be proposed that $\mathrm{TiOF}_{2}$ is an important intermediate product and may play an important role in the formation of our unique anatase $\mathrm{TiO}_{2}$ nanosheets. All the results indicate that the $\mathrm{TiOF}_{2}$ is the only product on the first reaction stage and then it dissolve gradually into the solvent. Only after this stage, can anatase $\mathrm{TiO}_{2}$ nanosheets begin to appear in the solid precipitates (Supporting Information, Fig. S5).

More importantly, Barnard et al have theoretically proved that for anatase $\mathrm{TiO}_{2}$, hydroxyl can lower the surface energy of $\{100\}$ facets and the oxygenated surface may lead to appearance of $\{100\}$ facets with a significant percentage. ${ }^{3}$ However, our synthetic condition is very different from these theoretical assumptions, which generally is in basic reaction medium. Thus the formation of high-energy $\{100\}$ facets in this work might be attributed to a different strategy. The lattice constants between the (100) plane of cubic $\mathrm{TiOF}_{2}$ (space group Pm3m, a,b,c=3.798 $\AA$ ) and the (100) plane of tetragonal anatase $\mathrm{TiO}_{2}$ (space group I41/amd, $a, b=3.7852 \AA$ and $c=9.5139 \AA$ ) is quite close along the [001] direction and the lattice mismatch is only $0.34 \%$ for $\{100\}$ facets of $\mathrm{TiOF}_{2}$ and anatase $\mathrm{TiO}_{2}$. This structural resemblance may be the root cause of the formation of $\{100\}$ facets in the large-sized anatase $\mathrm{TiO}_{2}$ nanosheets (overall percentage $=1.3 \%$ ) other than thermodynamically stable $\{101\}$ facets. That is, the solid $\mathrm{TiOF}_{2}$ acts as rigid "hard templates" to generate the thermodynamically unfavorable crystal facets of anatase $\mathrm{TiO}_{2}$. The hydrogen $\left(\mathrm{H}_{2}\right)$ evolution rate from photochemical reduction of water by using the products with a reaction time of $24 \mathrm{~h}$ (see Fig. S6 and S7 in Supporting Information) was also tested and the enhanced property might be attributed to the existence of high-reactive $\{001\}$ and $\{100\}$ facets.

In summary, large anatase $\mathrm{TiO}_{2}$ nanosheets wholly dominated by high-reactive $\{001\}$ and $\{100\}$ facets were synthesized by a solvothermal route. The adsorption of HF on the crystal surface determines the high percentage of $\{001\}$ facets while the perfect lattice match between anatase $\mathrm{TiO}_{2}$ and $\mathrm{TiOF}_{2}$ along [100] crystallographic direction promote the generation of high-energy of $\{100\}$ facets instead of other thermodynamically facets such as $\{101\}$ of anatase $\mathrm{TiO}_{2}$. The as-synthesized products exhibit superior photocatalytic property in contrast with the sample with $47 \%\{001\}$ facets. Besides the traditional applications in the areas such as environment and clean energy, the unique lamellar structure of anatase $\mathrm{TiO}_{2}$ prepared in this work might pave the way to extend the applications of $\mathrm{TiO}_{2}$ into other areas such as functional coatings, devices, or model samples for fundamental surface science. Furthermore, the present work also motivates us to explore new synthetic methods for the preparation of tailored crystal facets of other functional metal oxides.

\section{Notes and references}

This work was financially supported by Pujiang Talents Programme and Major Basic Research Programme of Science and Technology Commission of Shanghai Municipality (09PJ1402800, 10JC1403200), Shuguang Talents Programme of Education Commission of Shanghai Municipality (09SG27), National Natural Science Foundation of China (20973059, 91022023, 21076076, 21073060), Fundamental Research Funds for the Central Universities (WJ0913001) and Program for New Century Excellent Talents in University (NCET-090347) and the Australian Research Council (ARC) through Discovery Project program (DP1095861, DP0987969).

1. N. Tian, Z. Y. Zhou, S. G. Sun, Y. Ding, Z. L. Wang, Science, $2007,316,732$.

2. X. G. Han, M. S. Jin, S. F. Xie, Q. Kuang, Z. Y. Jiang, Y. Q. Jiang, Z. X. Xie, L. S. Zheng, Angew. Chem. Int. Ed., 2009, 48, 9180.

3. A. S. Barnard, L. A. Curtiss, Nano Lett., 2005, 5, 1261.

4. A. Fujishima, K. Honda, Nature, 1972, 238, 37.

5. M. Grätzel, Nature, 2001, 414, 338.

6. A. L. Linsebigler, G. Lu, J. T. Yates, Jr. Chem. Rev., 1995, 95, 735 .

7. J. S. Chen, X. W. Lou, Electrochemistry Communications, 2009, 11, 2332.

8. S. W. Liu, J. G. Yu, M. Jaroniec, J. Am. Chem. Soc., 2010, 132, 11914.

9. X. Q. Gong, A. Selloni, J. Phys. Chem. B, 2005, 109, 19560.

10. M. Lazzeri, A. Vittadini, A. Selloni, Phys. Rev. B, 2001, 63, 155409.

11. M. Lazzeri, A. Vittadini, A. Selloni, Phys. Rev. B, 2002, 65, 119901.

12. H. G. Yang, C. H. Sun, S. Z. Qiao, J. Zou, G. Liu, S. C. Smith, H. M. Cheng, G. Q. Lu, Nature, 2008, 453, 638.

13. H. G. Yang, G. Liu, S. Z. Qiao, C. H. Sun, Y. G. Jin, S. C. Smith, J. Zou, H. M. Cheng, G. Q. Lu, J. Am. Chem. Soc., 2009, 131, 4978.

14. X. G. Han, Q. Kuang, M. S. Jin, Z. X. Xie, L. S. Zheng, J. Am. Chem. Soc., 2009, 131, 3152; J. G. Yu, L. F. Qi and M. Jaroniec, J. Phys. Chem. C, 2010, 114, 13118; Q. J. Xiang, K. L. Lv and J. G. Yu, Appl. Catal. B: Environ., 2010, 96, 557; Z. K. Zheng, B. B. Huang, X. Y. Qin, X. Y. Zhang, Y. Dai, M. H. Jiang, P. Wang and M. H. Whangbo, Chem. Eur. J., 2009, 15, 12576; G. Mogilevsky, Q. Chen, H. Kulkarni, A. Kleinhammes, W. M. Mullins and Y. Wu, J. Phys. Chem. C, 2008, 112, 3239; J. G. Yu, J. J. Fan and K. L. Lv, Nanoscale, 2010, 2, 2144; J. S. Chen, Y. L. Tan, C. M. Li, Y. L. Cheah, D. Luan, S. Madhavi, F. Y. C. Boey, L. A. Archer and X. W. Lou, J. Am. Chem. Soc., 2010, 132, 6124; X. G. Han, Q. Kuang, M. S. Jin, Z. X. Xie and L. S. Zheng, J. Am. Chem. Soc., 2009, 131, 3152.

15. J. S. Chen, Y. L. Tan, C. M. Li, Y. L. Cheah, D. Y. Luan, S. Madhavi, F. Y. C. Boey, J. Am. Chem. Soc., 2010, 132, 6124.

16. J. M. Li, D. S. Xu, Chem. Commun., 2010, 46, 2301.

17. D. Q. Zhang, G. S. Li, X. F. Yang, J. C. Yu, Chem. Commun., 2009, 4381.

18. M. Min, L. Y. Piao, L. Zhao, S. T. Ju, Z. J. Yan, T. He, C. L. Zhou, W. J. Wang, Chem. Commun., 2010, 46, 1664.

19. G. Liu, H. G. Yang, X. W. Wang, L. N. Chen, H. F. Lu, L. Z. Wang, G. Q. Lu, H. M. Cheng, J. Phys. Chem. C, 2009, 113, 21784 .

20. F. Amano, O. O. Prieto-Mahaney, Y. Terada, T. Yasumoto, T. Shibayama, B. Ohtani, Chem. Mater., 2009, 21, 2601.

21. H. G. Yang, H. C. Zeng, J. Phys. Chem. B, 2004, 108, 3492.

22. T. Ohsaka, J. Phys. Soc. Jpn., 1980, 48, 1661. 